Drofdzik, and KrzysztofWofniak (2016) "A Comparative Chemical Study of Calcium SilicateContaining and Epoxy Resin-Based Root Canal Sealers". elsevierhealth,

7. Sasha Dimitrova-Nakova, Emel Uzunoglua, Hector Ardila-Osorioa, Anne Baudrya, Gilles Richardb, Odile Kellermanna, Michel
Goldberga (2015) "In vitro bioactivity of BiorootTM RCS, via A4 mouse pulpal stem cells".

8. Silva Almeida LH, Moraes RR, Morgental RD, Pappen FG (2017) "Are Premixed Calcium Silicate-based Endodontic Sealers Comparable to Conventional Materials? A Systematic Review of In Vitro Studies". J Endod, 43 (4), 527-535.

\title{
THỰC TRANG TIẾP THU KIẾN THỨC MODULE HỆ CƠ QUAN CỦA SINH VIÊN NĂM THỨ HAI CHƯƠNG TRÌNH ĐỔI MỚI NGÀNH Y TẠI TRƯỜNG ĐẠI HỌC Y DƯỢC THÁI NGUYÊN
}

\author{
Nguyễn Thị Bình ${ }^{1}$, Trịnh Xuân Đàn ${ }^{1}$, Nguyễn Thị Sinh ${ }^{1}$, \\ Hoàng Thị Lệ Chi ${ }^{1}$, Đoàn Thị Nguyệt Linh ${ }^{1}$.
}

\section{TÓM TẮT}

Mục tiêu: Đánh giá thực trạng tiếp thu kiến thức Module hệ cơ quan của sinh viên năm hai chương trình đổi mới ngành y khoa tại trường Đại học $Y$ Dược Thái Nguyên. Đối tượng và phương pháp: Mô tả cắt ngang, nghiên cưư định lượng kết hợp định tính tất cả sinh viến y khoa năm thứ 2 sau khi hoàn thành 6 module hệ cơ quan theo chương trình đổi mới ngành y khoa. Kết quả: Qua khảo sát 343 SV: 100\% sinh viên truy cập vào khóa học trên hệ thống Elearning, 86\% sinh viên truy cập elearning đọc đề cương chi tiết, hướng dẫn học tập, lịch học trước khi bắt đâu học mối module; $70 \tilde{\tilde{x}}-80 \%$ sinh viên truy cập elearning xem bài giảng mấu, ca lâm sàng, tài liệu tham khẳo. Tỷ lệ sinh viên chủ động chuẩn bị bài trước mỗi buối hoc theo đúng hướng dẫn họ tâp chiếm 70,3\%; sinh viên tham gia thảo luận nhóm chiếm 74,9\%; tỉ lê sinh viên trả lời được các câu hỏi trong giờ thảo luận ca lâm sàng là $51,3 \%$. Kết quả học tập các module của sinh viên: $97 \%$ sinh viên đạt (điểm > 4,0), chỉ có $3 \%$ số sinh viên không đạt (điểm $<4,0)$ và chiếm tỉ lệ cao nhất là ở mức trung bình $48,7 \%$, số sinh viên giỏi chiếm $4 \%$ và sinh viên kém chiếm 3,05\%. Trong 6 module thì module tiết niệu có số sinh viên đạt kết quả khá là cao nhất 149 sinh viên chiếm $37 \%$ và chỉ có 2 sinh viên là có kết quả kém. Số sinh viên đạt xuất sắc ( 5 sinh viên) và giỏi (67 sinh viên) cũng chiếm tỉ lệ cao nhất. Kết luận: Phương pháp giảng dạy tích cực/ lồng ghép các kiến thức y học cớ sở và lâm sàng đã thúc đây được sự chủ động cững như sự hứng thú hơn của sinh viên trong quá trình tiếp thu các kiến thức các môn tiền lâm sàng. Vì vậy, phương pháp giảng dạy đổi mới này có thể thay thế phương pháp giảng dạy truyền thống cho đối tượng sinh viên y khoa năm thứ 2 nhưng cần có sự điều chỉnh cho hợp lý để nâng cao chất lượng đào tạo, đạt được chuẩn đầu ra của nhà trường.

${ }^{1}$ Trường Đại hoc Y Dược Thái Nguyên

Chịu trách nhiệm chính: Nguyễn Thị Bình

Email:nguyenbinhydtn@gmail.com

Ngày nhận bài: 23/2/2021

Ngày phản biên khoa hoc: 9/3/2021

Ngày duyệt bài: 1/4/2021
Tư khóa: Hệ thống module, lồng ghép, học tập dựa trên vấn đề.

\section{SUMMARY \\ THE REALITY ACQUIRE KNOWLEDGE ORGAN SYSTEM MODULES OF THE $2^{\text {ND }}$ STUDENTS STUDY UNDER MEDICAL INDUSTRY INNOVATION PROGRAM AT THAI NGUYEN UNIVERSITY OF MEDICINE AND PHARMACY}

Objectives: To evaluate the reality acquire knowledge organ system modules of the $2^{\text {nd }}$ students study under medical industry innovation program at thai nguyen university of medicine and pharmacy. Subjects and methods: A cross-sectional study, quantitative study combined qualitative all the $2^{\text {nd }}$ medical students when they finished 6 organ system modules under the innovation program. Research results: Through a survey of 343 students: $100 \%$ of students access the course on Elearning system; $86 \%$ of students accessing Elearning read the detailed outline, study guides, study schedule before the start of each module; $70-80 \%$ of students accessing elearning view sample lectures, clinical cases and reference materials. Students actively prepare lesson according to the right instructions occupy 70,3\%; students participate in discussion groups accounted for 74,9\%; $51,3 \%$ of students answering questions during clinical case discussion. The result of the study module students: $97 \%$ of students passed (mark $>4.0$ ) only $3 \%$ of students failed (mark<4.0) and accounting for the highest percentage is at an average of $48.7 \%$; good student of $4 \%$ and accounted for $3.05 \%$ poor students. Among the 6 modules, the urinary module has the highest number of students with quite results 149 students, accounting for $37 \%$ and only 2 students had poor results. The number of excellent students ( 5 students) and good students (67 students) also accounted for the highest percentage. Conclusion: Integrated modular medical curriculum between basic and clinical medical knowledge has promoted the initiative as well as more excitement of students in the process of acquiring pre-clinical knowledge. So, this teaching method can replace the traditional system for 
the 2nd year medical students, but it is necessary to make reasonable adjustments to improve the quality of training and achieve the first standard of the School.

Keywords: Module systems, problem-based learning.

\section{I. ĐẶT VẤN ĐỀ}

Để đáp ứng các yêu cầu của hệ thống chăm sóc sức khỏe hiện đại, giáo dục y tế đã trải qua một quá trình chuyển từ giảng dạy truyền thống sang giáo dục y tế tích hợp dựa năng lực $[3,6,7]$. Việc học tập của sinh viên đạt hiệu quả cao nhất khi các kiển thức được lồng ghép/ tích hợp một cách logic giữa các môn tiên lâm sàng và lâm sàng. Các nhà giáo dục nhận ra rằng cần có sự tích hợp khoa học y học cơ sở và lâm sàng, loại bỏ các ranh giới giữa các môn cơ sở với các môn lâm sàng như trong cách giảng dạy truyền thống [4].

Phương pháp giảng dạy truyền thống chủ yếu lấy giáo viên làm trung tâm và việc giảng dạy các kiến thức cơ sở thiếu liên quan đến lâm sàng. Phương pháp giảng dạy tích hợp dựa trên năng lực lấy người học làm trung tâm đã thu hút sự chú ý của sinh viển và tạo ra nhiều hứng thú trong học tập [2]. Người ta đã quan sát thấy rằng sinh siên được đào tạo theo chương trình giảng dạy tích hợp đưa ra chẩn đoán chính xác hơn so với sinh viên được đào tạo theo chương trình giảng dạy truyền thống. Trong những năm gần đây, các chương trình giảng dạy đổi mới này đã được thực hiện ở các khoa của nhiều trường y trên thế giới, bao gồm cả các nước Nam A $[1,3,4]$. Hơn thế nữa, tích hợp dọc giữa các khoa y học cơ sở lâm sàng theo hình thức 'Hoc tâp dựa trên vấn đề' (PBL) đã kích thích sự hiểu biểt tốt hơn về các nguyên tắc y sinh so với các các chương trình giảng dạy truyền thống. Học tập tích hợp là nhu câu của cấp thiết.

Tại Việt Nam, với sự hố trợ của Tổ chức Hợp tác vì sự phát triển $y$ tế Việt Nam/The Partnership for Health Advancement in Vietnam (HAIVN) và Dự án Giáo dục Đào tạo Nhân lực Y tế phục vụ cải cách y tế/Health Professionnal Education and Training Project (HPET), rất nhiều trường y trong cả nước đã và đang xây dựng và đưa vào giảng dạy theo hình thức tích hợp/ lồng ghép giứa các môn y học cơ sở và lâm sàng, trong đó có trường Trường Đại học $Y$ - Dược, Đại học Thái Nguyên của chúng tôi.

Chương trình đào tạo Bác sĩ $Y$ khoa hê đại học chính qui của Trường Đại học $Y$ Dược Thái Nguyên thực hiện mục tiêu đào tạo: sau khi tốt nghiệp, sinh viên có thể đáp ứng được nhu cầu đòi hỏi về trình độ chuyên môn của ngành nghề theo chuẩn đầu ra cũng như nhu cầu phục vụ cho xã hội về khám, chữa bệnh và phòng bệnh cho nhân dân. Theo đó, chương trình đào tạo 6 năm cho sinh viên bác sĩ đa khoa thì các mổn $Y$ học cơ sở là những môn đầu tiên và tiền đề cho các em sinh viên trong 3 năm đầu trước khi bước sang các môn lâm sàng tại bệnh viện. Do đó, các bộ môn trong Khoa Y học cớ sở luôn cố gắng thay đổi phương pháp dạy học và cập nhật nhiều kiến thức mới nhằm giúp sinh viên có thể dễ hiểu hơn và thấy được tầm quan trọng của các môn học này. Với sự hỗ trợ của Tổ chức HAIVN và Dự án HPET, Nhà trường đang thực hiện đổi mới chương trình đào tạo bác sĩ y khoa theo hướng lồng ghép/tích hợp dựa trên năng lực thực hành nghề nghiệp. Khoa $Y$ học cơ sở chúng tôi cũng đã tham gia xây dựng Module theo các hệ cơ quan có lồng ghép/ tích hợp kiến thức các bộ môn trong khoa $Y$ học cở sở với nhau. Sau 3 năm triển khai hoạt động của Dự án, 6 module: Huyết học- bạch huyêt, hệ tim mạch, hệ hô hấp, hệ tiêu hóa, hệ tiết niệu, Dacơ- xương đã được hoàn thiện và đưa vào giảng dạy cho sinh viên Bác sỹ đa khoa năm thứ hai, năm học 2019-2020. Vì đây là phương pháp giảng dạy mới có sự lồng ghép kiến thức các môn y học cơ sở dưới dạng các case lâm sàng nên trong quá trình thực hiện sẽ có những thuận lợi cũng như khó khăn trong việc tiếp thu kiến thức của sinh viên so với phương pháp giảng dạy truyền thống trước đây. Vì vậy, chúng tôi tiến hành đề tài này nhằm mục tiều: Đánh giá thực trạng tiếp thu kiến thức Module hê cơ quan của sinh viên năm hai chương trinh đổi mới ngành y khoa tại trường Đại học Y Dược Thái Nguyên

\section{II. ĐỐI TƯợNG VÀ PHƯƠNG PHÁP NGHIÊN CỨU}

\section{1. Đối tượng nghiên cứu}

- Tất cả sinh viên y khoa khóa 51 và chuyên tu y khóa $50 \mathrm{~A}$ sau khi hoàn thành 6 module hệ cơ quan theo chương trình đổi mới ngành y khoa, năm học $2019-2020$

\subsection{Phương pháp nghiên cứu}

- Phương pháp nghiên cứu: mô tả cắt ngang, nghiên cứu định lượng kết hợp định tính.

- Thời gian và địa điểm nghiên cứu:Nghiên cứu tiến hành từ tháng 1 đến tháng 10 năm 2020 tại Trường Đại học Y Dược - Đại học Thái Nguyên

- Chỉ tiêu nghiên cứu:

*Đánh giá thực trạng tiếp thu kiến thức Module hệ cơ quan của sinh viên năm hai chương trình đổi mới ngành y khoa tại trường Đại học Y Dược Thái Nguyên.

+ Điểm thi hết học phần tất cả các sinh viên BSĐK khóa 51 và chuyên tu Y khóa 50 năm học 2019- 2020.

+ Phiếu khảo sát sinh viên về các việc tự học 
và kiến thức sinh viên tiếp thu được sau khi học xong các Module này.

- Xử lý số liệu: Thống kê y học trên phần mên SPSS 20.0

\section{KẾT QUẢ NGHIÊN CỨU VÀ BÀN LUÂ̂N}

Có 343 sinh viên (84\%) đã trả lời bảng câu hỏi (bảng 1 và bảng 2).

Bảng 1. Ti lệ sinh viên tiếp cận các tài liệu học tập của các module

\begin{tabular}{|c|c|c|}
\hline Câu hỏi & $\begin{array}{l}\text { Số sinh } \\
\text { viên }\end{array}$ & $\begin{array}{l}\text { Tỉ lệ } \\
\%\end{array}$ \\
\hline Tỷ lệ SV truy cập vào các & & \\
\hline $\begin{array}{c}\text { khóa học module hệ cơ quan } \\
\text { trên hệ thống elearning }\end{array}$ & 343 & 100 \\
\hline $\begin{array}{l}\text { Tỷ lệ SV truy cập elearning } \\
\text { đọc đề cương chi tiết, lịch } \\
\text { hoc, hướng dẫn hoc tấp }\end{array}$ & 295 & 86 \\
\hline $\begin{array}{l}\text { Tỳ lệ SV truy cập elearning } \\
\text { đọc nội dung ca lâm sàng và } \\
\text { các yêu câuu liên quan đến ca } \\
\text { lâm sàng }\end{array}$ & 279 & 81,3 \\
\hline $\begin{array}{l}\text { Tỷ lệ SV truy cập elearning } \\
\text { đọc nội dung bài giảng, slide } \\
\text { bài giảng... }\end{array}$ & 241 & 70,3 \\
\hline $\begin{array}{l}\text { Tỷ lệ SV truy cập eleaning } \\
\text { làm bài pretest theo lich }\end{array}$ & 336 & 98 \\
\hline $\begin{array}{l}\text { Tỷ lệ SV truy cập elearning } \\
\text { đọc và tải tài liệu tham khảo } \\
\text { môn học }\end{array}$ & 243 & 70,8 \\
\hline
\end{tabular}

Bảng 2. Tì lệ sinh viên tự họ ở nhà và trên lớp khi họ các module

\begin{tabular}{|c|c|c|}
\hline Câu hỏi & \begin{tabular}{|l} 
Số sinh \\
viên
\end{tabular} & $\begin{array}{c}\text { Tỉ lệ } \\
\%\end{array}$ \\
\hline $\begin{array}{l}\text { Tỷ lệ SV chuẩn bị bài theo } \\
\text { hướng dẫn học tập }\end{array}$ & 241 & 70,3 \\
\hline $\begin{array}{c}\text { Tỷ lệ sinh viên tự trả lời được } \\
\text { nội dung câu hỏi trong phần } \\
\text { hướng dẫn học tập }\end{array}$ & 227 & 66,2 \\
\hline $\begin{array}{l}\text { Tỷ lệ sinh viên trả lời được các } \\
\text { câu hỏi của giảng viên trong } \\
\text { giờ lý thuyết. }\end{array}$ & 246 & 71,7 \\
\hline $\begin{array}{l}\text { Tỉ lệ sinh viên tham gia thảo } \\
\text { luận nhóm theo các ca lâm sàng }\end{array}$ & 257 & 74,9 \\
\hline $\begin{array}{l}\text { Tỉ lệ sinh viên trả lời được các } \\
\text { câu hỏi trong giờ thảo luận ca }\end{array}$ & 176 & 51,3 \\
\hline
\end{tabular}

\begin{tabular}{|c|c|c|}
\hline lâm sàng & & \\
\hline $\begin{array}{c}\text { Tỉ lệ sinh viên phản hồi lại thây } \\
\text { cô khi có những thắc mắc liên } \\
\text { quan đến nội dung bài học }\end{array}$ & 231 & 67,3 \\
\hline
\end{tabular}

Qua bảng 1 trên ta thấy, tỷ lệ sinh viên truy cập vào khóa học trên hệ thống Elearning chiếm $100 \%, 86 \%$ sinh viên truy cập elearning đọc đề cương chi tiết, hướng dẫn học tập, lịch học trước khi bắt đầu học mỗi module; $70-80 \%$ sinh viên truy cập elearning xem bài giảng mẫu, ca lâm sàng, tài liệu tham khảo. Như vậy, sinh viên đã rất tích cực tiếp cận tài liệu học tập của các module. Mặt khác, bài giảng được thiết kế khá sinh động, phong phú, logic thu hút và đáp ứng được nhu câu của người học. Tuy nhiên còn một tỉ lệ nhỏ sinh viên chưa thực sự chủ động hoặc gặp khó khăn khi tiếp cận các tài liệu học tập trên hệ thống; theo phản hồi chúng tôi cũng nhận được, một số sinh viên cho rằng một số module việc đưa các tài liệu học tập lên hệ thống sát với thời gian bắt đầu khóa học, hệ thống mạng đôi khi còn chậm khi tất cả sinh viển đồng loạt truy cập elearning đọc tài liệu và làm các bài kiểm tra pretest online.

Theo kết quả bảng 2,70,3\% sinh viên chủ động chuẩn bị bài trước mỗi buổi học theo đúng hướng dẫn học tập. Sinh viên tham gia thảo luận nhóm chiếm $74,9 \%$; tuy nhiên tỉ lệ sinh viên trả lời được các câu hỏi trong giờ thảo luận ca lâm sàng là $51,3 \%$ có thể do các em chỉ quan tâm và tìm hiểu nội dung thảo luận của nhóm mình mà không tìm hiểu về các nội dung thảo luận của các nhóm khác, sinh viên cũng vẫn còn khá bị động trong quá trình tự học và hoạt động thảo luân trên lớp, nhiều bạn sinh viên vẫn học theo kiểu đối phó. Như vậy, với kết quả trên chúng tôi thây rằng sinh viên đã chủ động hơn trong việc tiếp cận tài liệu cũng như các kiến thức các mổn tiền lẩm sàng theo hướng tích hợp/lồng ghép. Điều đó chứng tỏ các em đã hứng thứ và dành nhiêu thời gian hơn cho việc tự học, cũng như chủ động hơn trong viêc tiếp thu các kiến thức và đã phần nào thấy được tầm quan trọng của môn học tiền lâm sàng.

- Kết quả học tập

Bảng 3. Tóm tắt kêt quả học tập

\begin{tabular}{|c|c|c|c|c|c|c|}
\hline MODULE (Số SV) & \multicolumn{7}{|c|}{ Điếm đạt sinh viên / số sinh viên (\%) } \\
\hline & $9,0-10(\%)$ & $8-8,9 n(\%)$ & $7,0-7,9(\%)$ & $5,5-6,9(\%)$ & $4,0-5,4$ & $<4,0(\%)$ \\
\hline HH-BH( $(\mathrm{n}=408)$ & $0(0 \%)$ & $6(1,5 \%)$ & $71(17,4 \%)$ & $233(57 \%)$ & $94(23,1 \%)$ & $4(1 \%)$ \\
\hline TIM MACH $(\mathrm{n}=404)$ & $1(0,3 \%)$ & $10(2,5 \%)$ & $89(22 \%)$ & $180(44,6 \%)$ & $108(26,6 \%)$ & $16(4 \%)$ \\
\hline HÖ HAिP( $\mathrm{n}=406)$ & $0(0 \%)$ & $1(0,3 \%)$ & $18(4,4 \%)$ & $185(45,6 \%)$ & $173(42,6 \%)$ & $29(7,1 \%)$ \\
\hline TIËU HOA $(\mathrm{n}=403)$ & $0(0 \%)$ & $11(2,7 \%)$ & $62(15,4 \%)$ & $220(54,6 \%)$ & $97(24,1 \%)$ & $13(3,2 \%)$ \\
\hline
\end{tabular}




\begin{tabular}{|c|c|c|c|c|c|c|}
\hline TIET NIËU(n=403) & $5(1,2 \%)$ & $67(16,6 \%)$ & $149(37 \%)$ & $144(35,7 \%)$ & $36(8,91 \%)$ & $2(0,5 \%)$ \\
\hline DA-CO'-XƯỚNG & & 3 & 36 & 220 & 134 & 12 \\
$n=405$ & & $0,7 \%$ & $8,9 \%$ & $54,3 \%$ & $33,1 \%$ & $3 \%$ \\
\hline Tống(2429) & $6(0,25 \%)$ & $98(4,1 \%)$ & $425(17,5 \%)$ & $1182(48,7 \%)$ & $642(26,4 \%)$ & $76(3,05 \%)$ \\
\hline
\end{tabular}

(Nguồn số liệu từ Phòng Đạo tạo )

Theo bảng trên ta thây khoảng $97 \%$ sinh viên đạt (điểm $>4,0$ ), chỉ có $3 \%$ số sinh viên không đạt (điểm $<4,0)$ và chiếm tỉ lệ cao nhất là ở mức trung bình $48,7 \%$, số sinh viên giỏi chiếm $4 \%$ và sinh viên kém chiếm $3,05 \%$.

Có thể nguyên nhân là do đây là khóa đầu tiên sinh viên được học theo phương pháp đổi mới có sự tích hợp/ lồng ghép giữa các môn tiền lâm sàng theo cả chiều dọc và chiều ngang. Giảng dạy lý thuyết được lồng ghép dưới dạng các case lâm sàng theo nhiều chặng và hình thức thảo luận nhóm nên sinh viên phải tích cực chủ động dành nhiều thời gian hơn trong việc tự học và làm viêc nhóm thì mới đat được kết quả học tập cao nhất. Hình thức lượng giá sinh viên bao gồm: các bài pretest để khuyến khích sinh viên tự đọc tài liệu trước mỗi buổi học lý thuyết, năng lực tự chủ và chịu trách nhiệm trong các bài thảo luận nhóm, thi giữa học phần và thi kết thúc học phần theo hình thức MCQ trên máy tính đã có sự khác biệt với phương pháp giảng dạy truyền thống trước đây cho nên sinh viên có thể chưa thực sự làm quen và có phương pháp học tập hiệu quả. Nguyên nhân khách quan nữa có thể chương trình hoc theo module của các môn tiền lâm sàng mới được xây dựng nên trong vấn đề về lồng ghép kiến thức giữa các môn Giải phẫu- sinh lý, Mô phôi- Giải phẫu bênh, sinh hóa- sinh lý bệnh... dưới dạng các ca lâm sàng nhiều phần còn chưa thực sự hợp lý và logic. Ngoài ra, một số module do ảnh hưởng của dịch COVID-19, phải giảng dạy online nên ít nhiều ảnh hưởng đến kết quả học tập của sinh viên. Do đó, trong thời gian sắp tới các thây cô tham gia xây dựng cũng như giảng dạy các module hề cơ quan sẽ phải rà soát lại tất cả các module và có sự điều chỉnh sao cho phù hợp để năng cao chất lượng đào tạo phù hợp với chuẩn đầu ra của Nhà̀ trường.

Trong 6 module hệ cơ quan thì module tiết niệu có số sinh viên đạt kết quả khá là cao nhất 149 sinh viên chiếm $37 \%$ và chỉ có 2 sinh viên là có kêt quả kém. Số sinh viên đạt xuất sắc (5 sinh viên) và giỏi (67 sinh viên) cũ̃ng chiếm tỉ lệ cao nhất. Điều này có thể do module tiết niệu được tổ chức dạy học vào học kỳ 2 của sinh viên, sau 4 module: huyết học- bạch huyết, tim mach, hô hấp, tiêu hóa nên sinh viên đã có môt khoảng thời gian làm quen và có thể bắt nhịp được với phương pháp học tích cực. Đồng thời, một số sinh viên có ý kiến rằng: "mỗi module hướng dẫn sinh viên tiếp cận khác nhau và chúng em thấy cách tổ chức của module Tiết niệu giúp sinh viên dễ tiếp cận hơn cả : kế hoạch chương trình học ngay từ đầu (kể cả nội dung thực hành và pretest); giảng viên giảng lý thuyết khái quát và nhấn mạnh nội dung cốt Iõi giúp sinh viên hình dung tổng quan và nắm bắt những nội dung chính trong môn học cũng như những vẩn đề hay gặp trên lâm sàng giúp chúng em có thể tiếp thu những kinh nghiệm của các thầy cô; sau đó vận dụng những những kiến thức đó để giải quyết case lâm sàng. Còn 1 số module giảng case ngay từ đầu, trong quá trình học có gì thắc mắc thì thầy cô cũng giải đáp nhưng nhiều khi chúng em cũng không biết hỏi gì, chúng em không biết trong hệ cơ quan này thì cái gì hay gặp trên lâm sàng mà hỏi...".

Mục tiêu cuối cùng của giáo dục y tế trong thời đại ngày nay là mang lại những quan điểm mới về nội dung, quy trình, mức độ và cách đánh giá chương trình giảng day y tế. Hêe thống module tích hợp gần đây đã được phát triển như một chiến lược quan trọng nhằm mục đích mang lại sự phối hợp trong các hoạt động dạy và học. Trong những năm gần đây, trên khắp thế giới, các chương trình giảng dạy tích hợp như vậy đã được các khoa trong các trường y tế sử dụng để giảng dạy cho sinh viên [3]. Các nhà giáo dục y khoa nhận ra rằng cần phải tích hợp khoa học cơ sở và lâm sàng [2] một cách khoa học mạnh mẽ sẽ thu hút sự chú ý của học sinh và tạo ra nhiều hứng thú hớn trong học tập. Các sinh viên được đào tạo với một chương trình giảng dạy tích hợp như vậy, chẩn đoán chính xác hơn những sinh viên được đào tạo theo chương trình truyền thống [1].

\section{KẾT LUẬN VÀ KHUYẾN NGH!}

Nghiên cứu này của chúng tôi bước đầu cho thây một cái nhìn bao quát về thực trạng tiếp thu kiến thức của sinh viên năm thứ 2 khi học theo chương trình đổi mới ngành y khoa. Đại đa số các sinh viên đã rất tích cực, chủ động trong quá trình học tập cũng như các sinh viên cảm thấy rất là hứng thú với phương pháp học mới này. Tuy nhiên, kết quả học tập của các em chưa thực sự cao do những nguyên nhân khách 
quan và chủ quan như đã phân tích ở trên cân phải được khắc phục và thay đổi để mang lại hiệu quả cao nhất cho người học.

Phương pháp giảng dạy đổi mới này có thể thay thế phương pháp giảng dạy truyền thống cho đối tượng sinh viên y khoa năm thứ 2 nhưng cần có sự điều chỉnh sao cho hợp lý để nâng cao chất lượng đào tạo và đạt được chuẩn đầu ra của Nhà trường.

Để có cơ sở cho việc điều chỉnh chương trình giảng dạy các module hệ cớ, chúng tôi khuyến nghị cần khảo sát phản hồi của sinh viên và giáo viên về từng module hê cơ quan, sự tương tác giữa giáo viên- sinh viên cũng như khối lượng kiến thức mà module truyền tải đến sinh viên.

\section{TÀI LIÊU THAM KHẢO}

1. Al- Damegh S, Baig LA. Comparison of an integrated problembased learning curriculum with the traditional discipline-based curriculum in KSA. J Coll Physicians Surg Pak 2005;15:605-8.

2. Custers EJ, Cate OT. Medical students' attitudes towards and perception of the basic sciences: a comparison between students in the old and the new curriculum at the University Medical Center Utrecht, The Netherlands. Med Educ 2003;36:1142-50

3.Ghosh S, Pandya HV. Implementation of integrated learning program in neurosciences during first year of traditional medical course: perception of students and faculty. BMC Med Educ 2008;8:44.

4. Muller JH, Jain $S$, Loeser $H$, Irby DM. Lessons learned about integrating a medical schoo curriculum: perceptions of students, faculty and curriculum leaders. Med Educ 2008;42:778-85.

5. Shimura $T$, Aramaki $T$, Shimizu $K$, Miyashita $\mathbf{T}$, Adachi $\mathbf{K}$, Teramoto A Implementation of integrated medical curriculum in Japenese medical schools. J Nippon Med Sch 2004;71:11-16.

6. Vyas $R$, Jacob $M$, Faith $M$, Isaac B, Rabi S, Sathishkumar $\mathbf{S}$, et al. An effective integrated learning programme in the first year of the medical course. Natl Med J India 2008;21:21-6.

7. Williams G, Lau A. Learning in practice. Reform of undergraduate medical teaching in the United Kingdom: a triumph of evangelism over common sense. Br Med J 2004;329:92-4

\section{NGHIÊN CỨU GIÁ TRI CỦA CHỤP CLVT TRONG CHẨN ĐOÁN VÀ ĐIỀU TRI BẢO TỒN CHẤN THƯO'NG GAN}

\section{TÓM TẮT}

Muc tiêu: Nghiên cứu giá trị của chup CLVT trong chẩn đoán và điều trị bảo tồn chấn thương gan. Đối tượng và phương pháp: Nghiên cứu mô tả cắt ngang hồi cứu, 51 bệnh nhân bị chấn thương gan, tại bệnh viện Nhân Dân 115 từ tháng $1 / 2017$ đến 12/2018. Kết quả: Đăcc điểm chung của đối tượng nghiên cứu: Nam 70,6\%; nữ 29,4\%; tuổi trung bình $33,65 \pm 14,17$; TNGT chiếm $82,4 \%$. Giá trị của cắt lớp vi tính trong điều trị bảo tồn chấn thương gan. Điều trị bảo tồn thành công $82,4 \%$; tắc mach $9,8 \%$; phấu thuật $7,8 \%$. Phẫu thuật và tắc mạch chủ yếu có độ tổn thương IV và V, chỉ 01 trường hợp đô III phẫu thuật do tổn thương rách túi mật đi kèm. Trong những trường hợp có huyết động ổn đinh: tổn thương độ I-II-III điêu trị bảo tồn 100\%; độ IV với $90 \%$ thành công và độ $V$ là $22,2 \%$. Tổn thương rách gan $100 \%$ bảo tồn thành công; dập gan 94,7\%; dập rách $72,4 \%$. Tỉ lệ điều trị bảo tồn thành công tî lệ nghich với mức độ dịch tự do trong ổ bung mức độ: nhiều $50 \%$; vưa $75 \%$ và ít $90,3 \%$. Kết luận: CLVT rất có giá trị trong chẩn đoán mức độ chấn thương gan,

*Trường Đại học Y khoa Phạm Ngọc Thạch. Chịu trách nhiệm chính: Đặng Vĩnh Hiệp

Email: hiepdv@pnt.edu.vn

Ngày nhận bài: 28/2/2021

Ngày phản biên khoa hoc: 25/3/2021

Ngày duyệt bài: 6/4/2021
Đặng Vĩnh Hiệp*

từ đó đưa ra các phương án điều trị phù hợp cho bệnh nhân. CLVT giúp chỉ định điều trị bảo tồn chấn thương gan được áp dụng nhiều hơn.

Tư khóa: Chấn thương gan, CLVT, điều trị bảo tồn chấn thương gan, nút mạch gan.

\section{SUMMARY}

\section{RESEARCH FOR VALUATION OF ABDOMINAL COMPUTED TOMOGRAPHY IN DIAGNOSTIC AND NONOPERATED TREATMENT OF LIVER TRAUMA}

Purpose: Research for valuation of abdominal computed tomography in diagnostic and nonoperated treatment of liver trauma. Subjects and method: Retrospective cross - sectional study of 51 liver trauma patients were diagnostic and treatment at People's Hospital 115, Ho Chi Minh City from 1/2017 to 12/2018. Results: Objective characteristics: Data from 51 patients, 36 males and 15 females (male/female $=2.4$ ) age for both sexes was 33,65 $\pm 14,17$. Traffic accident was $82.4 \%$. Valuation of abdiminal computed tomography for non - operated treatment liver trauma: Treatment success rate in liver trauma: $82.4 \%$ with non - operating, 9.8\% with embolization interventions, $7.8 \%$ with operation. Surgery and embolism mainly has damage in grade IV and V level, only 01 case of grade III surgery due to associated disection gallbladder trauma.. In the cases of hemodynamics stability: level I-II-III injury conservative treatment $100 \%$; Grade IV with $90 \%$ success and $\mathrm{V}$ level $22.2 \%$. Liver damage is 